\title{
Utilization of Smart Grid and Renewable Energy toward a Sustainable Future in Saudi Arabia
}

\author{
Alghanim. M.H. ${ }^{1}$, Mallick. P.K ${ }^{2}$ \\ ${ }^{1}$ Energy Systems Engineering \\ University of Michigan- Dearborn, MI, 48128, USA. \\ e-mail: malghani@umich.edu \\ ${ }^{2}$ A professor of Mechanical Engineering and the director of Energy Systems Engineering \\ University of Michigan- Dearborn, MI, 48128, USA. \\ e-mail: pkm@umich.edu
}

\begin{abstract}
Saudi Arabia is currently the largest oil producing and oil-exporting country in the world, but it also has a strong potential for renewable energy, particularly solar energy as it receives a significant amount of sunlight during most of the year. As demand for electricity increases with increasing population, energy becomes one of the main challenges in Saudi Arabia. As a result, infrastructure for different energy resources needs to be developed and integrated smartly into the country's electricity grid. This paper discusses the reasons to implement smart grid in Saudi Arabia, and the challenges and opportunities of utilizing renewable energy in conjunction with smart grid.
\end{abstract}

\section{Key words}

Saudi Arabia, Smart Grid, Renewable Energy, Solar Energy

\section{Introduction}

Energy is an integral part of people's lives at home, at work and on road. Energy is used in agriculture, manufacturing, construction, and many other industries. Furthermore, demand for energy is increasing with increasing use of technology, for example in automated machineries, communication devices, computers, and cars. Correspondingly, as the demand for energy increases, so does the need to develop multiple sources of energy, particularly the renewable and more environment-friendly energy. In this paper, the energy issues in Saudi Arabia are examined in view of its unique position in the world as the largest oil exporter and at the same time, the challenges it faces to meet growing demand of energy among its population.

Saudi Arabia's current population is close to $29,000,000$ and, while it is increasing at an annual rate of $1.5 \%$, its energy demand is increasing at an annual rate of $8 \%$ [1]. The availability of energy to match the demand has thus become one of the main challenges in Saudi Arabia. On other hand, according to several forecasts, Saudi Arabia's oil revenue, which depends mainly on petroleum export [2], is expected to decline in the near future. For this reason, Saudi Arabia has recently formulated an energy policy in which $54 \mathrm{GW}$ will be generated from renewable sources by 2032, out of which $41 \mathrm{GW}$ will come from solar energy and the remaining 13 $\mathrm{GW}$ will come from wind and other renewable energy sources [3], [4]. It is expected that diversification of energy supply will not only meet the future energy demand in the country, but may also make Saudi Arabia a leader in exportation of renewable energy. Adoption of renewable energy will reduce greenhouse gas emission and promote economic growth. Accordingly, Saudi Arabian government has announced an investment of $\$ 109$ billion for the next 18 years, which will be spent on research and development in the renewable energy field [4].

Setting goals in the renewable energy field is both complex and uncertain within the announced time frame of its adoption by 2032. It not only depends on financial resources, but also on the relative merits and risks of different forms of renewable energy with respect to cost and the level of available technology. The current grid system may not accept renewable energy very well, which is also a factor to consider. This paper addresses the issues involved in upgrading the current traditional grid system to smart grid system and adopting solar power to augment the electricity generation.

\section{Status of Oil in Saudi Arabia}

Saudi Arabia is one of the top five oil producing countries in the world [5]. It has 17\% of the world's petroleum reserve and it is also the largest exporter of petroleum in the world. Saudi Arabia's economy depends mainly on oil exportation. The petroleum sector of Saudi Arabia accounts for close to $80 \%$ of its budget revenues, $45 \%$ of its GDP and $90 \%$ of its export earnings. The average oil production in Saudi Arabia was 11.6 million barrels per day in 2011, out of which 9.8 million was from crude oil and 1.8 million was from natural gas liquids and other liquids.

The oil consumption in Saudi Arabia in 2011 was 3 million barrels/day, which was double the amount consumed in 2000 [6]. The principal factor contributing to increasing oil consumption is increasing demand of 
electricity which is due to industrial growth in the petrochemical sector, high usage of air-conditioners in summer months, and heavily subsidized electricity price. Increasing oil demand within the country will eventually affect the oil export and foreign revenue unless a variety of other energy sources are utilized to generate electricity. According to the CEO of Saudi Aramco, if half of the electricity comes from renewable energy in 2020, 3 million barrels of oil can be saved per day [7].

According to the U.S Energy Information Administration, Saudi Arabia has exported around 7.5 million barrels/d of crude oil in 2012 [6]. However, it is projected that the oil export will decline at an average rate of $4.73 \%$ per year (Figure 1). The principal reasons for decline in oil export are increasing demand of oil for domestic consumption and growing supply and discovery of new resources of oil and natural gas in countries such as USA and Canada. It is projected that if the current situation continues, the domestic oil need in Saudi Arabia will be equal to the oil production in in 2030 so that thereafter, Saudi Arabia will have to import oil from outside sources.

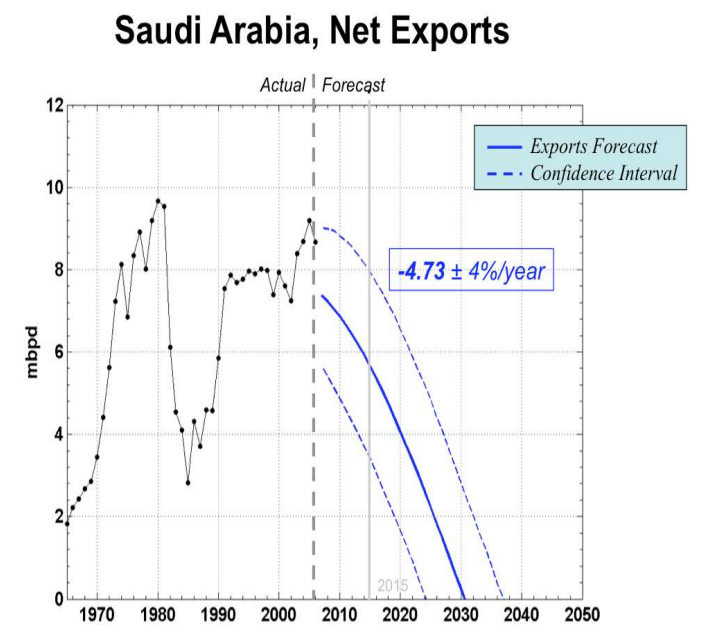

Figure 1: Net oil export of Saudi Arabia in millions of barrels per day [5]

\section{Electricity in Saudi Arabia}

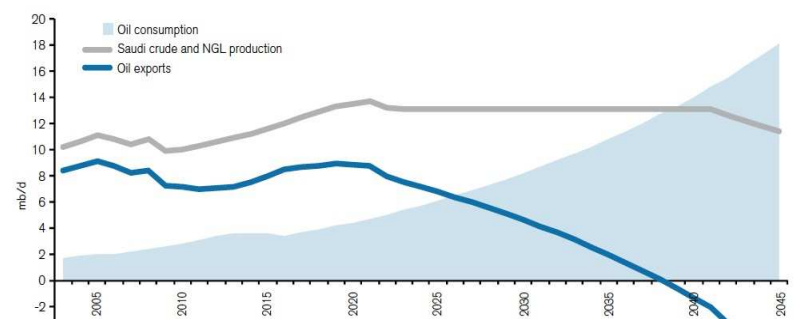

Figure 2: Consumption, production, and export of oil from 2000 to 2045

[7]

The electricity generation in Saudi Arabia is mainly based on oil, natural gas and their byproducts. Close to $99 \%$ of the households are connected to the electric grid. The electric power system is geographically divided into four operating sectors, namely Eastern, Central, Western, and Southern. The industry and population are concentrated mostly in the lower western, southern and middle of the eastern sectors. The capital of the country, Riyadh, is located in the central sector and other notable cities, such as Jeddah, Mecca and Madinah, are in the western sector. Vast area in the central and upper eastern sectors is desert and is very thinly populated.

In 2012, Saudi Arabia's rated capacity in the power sector was close to $50 \mathrm{GW}$. The electricity generation and consumption were 239.23 billion $\mathrm{kWh}$ and 190.88 billion $\mathrm{kWh}$, respectively. The 2009 data show that the electricity consumptions in the residential and commercial sectors were 47 and $24 \%$, respectively, and only $9 \%$ was in the industrial sector. The electricity demand in Saudi Arabia is growing at a rate of $8 \%$ per year, while the population growth rate is $1.5 \%$ [1]. Per capita electricity consumption rate has increased at an annual rate of $4.7 \%$ between 1990 and 2000 and $6.5 \%$ between 2000 and 2008. One reason for higher electricity demand is that the country as a whole is becoming more affluent, which can be seen in its per capita GDP increase from US \$9,354 in 2000 to US $\$ 20,778$ in 2011. To reduce the unemployment rate, its industrial sector, particularly in the manufacturing area, is being diversified and expanded. Another reason is the country's population demographics. The age group of 24 to 54 represents $44.6 \%$ of the population and the age group of 15 to 24 represents $19.8 \%$ compared to only $4 \%$ in the 55 and older age group [1]. The higher percentage of young population makes the electricity demand problem even more critical, since they are either using or will be using increasing number of electricity-dependent advanced technology as they grow older.

Assuming that the electricity consumption in Saudi Arabia will increase due to population growth and per capita electricity consumption, the following simple model is used to project the electricity consumption in the next 25 years.

$$
C_{n}=C_{o}\left(1+r_{1}\right)^{n}\left(1+r_{2}\right)^{n}
$$

where, $C_{n}=$ electricity consumption in $n$ years, $C_{o}=$ current or initial electricity consumption, $r_{1}=$ population growth rate per year, and $r_{2}=$ per capita electricity consumption growth rate per year. Equation (1) is plotted in Figure 3 for $r_{2}=6 \%$ and $r_{1}=1.5,2$ and $2.5 \%$, and in Figure 4 for $r_{1}=1.5 \%$ and $r_{2}=1.5$ to $10 \%$. Assuming that the per capita electricity growth rate is $6 \%$ (Figure 3 ), the electricity consumption in 2038 will vary between 1190 to 1520 billion $\mathrm{kWh}$ for population growth rate ranging between 1.5 and $2.5 \%$. Similarly, assuming that the current population growth rate of $1.5 \%$ will continue (Figure 4), the electricity consumption in 2038 will vary between 402 to 3003 billion $\mathrm{kWh}$ for electricity growth rate ranging between 1.5 and $10 \%$. In both Figures 3 and 4 , the 2013 electricity consumption is assumed as 191 billion $\mathrm{kWh}$. At the present rate of $r_{1}=1.5 \%$ and $r_{2}=8 \%$, the electricity consumption in 2038 will be 1898 billion $\mathrm{kWh}$, which is nearly 10 times the current electricity consumption. 


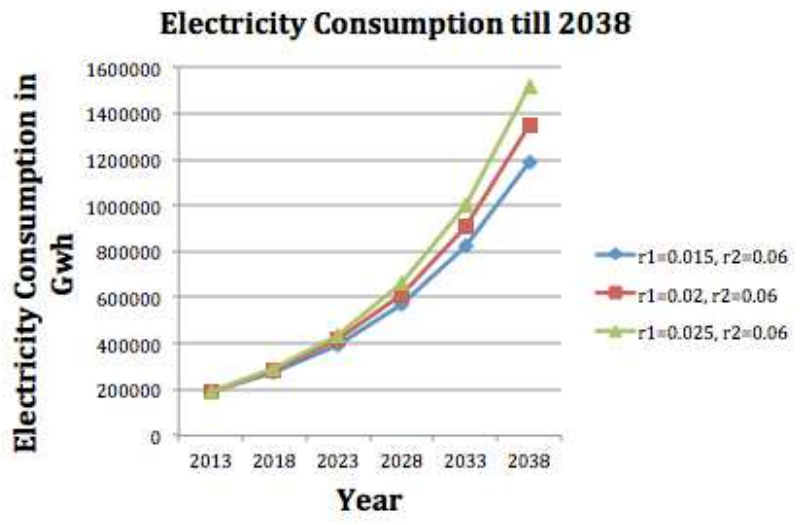

Electricity Consumption Per Capita

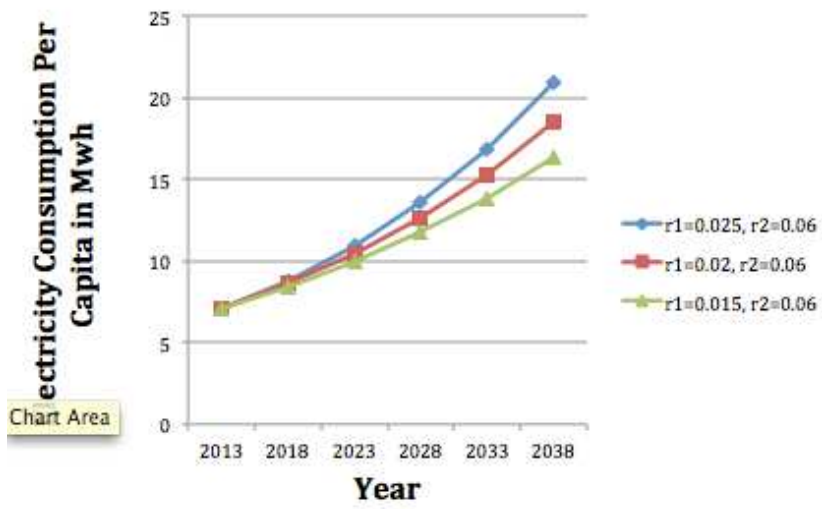

Figure 3: Projected total electricity consumption (top) and per capita electricity consumption (bottom) as calculated using Equation (1) and assuming $r_{l}=0.015,0.02$ and 0.025 and $r_{2}=0.06$
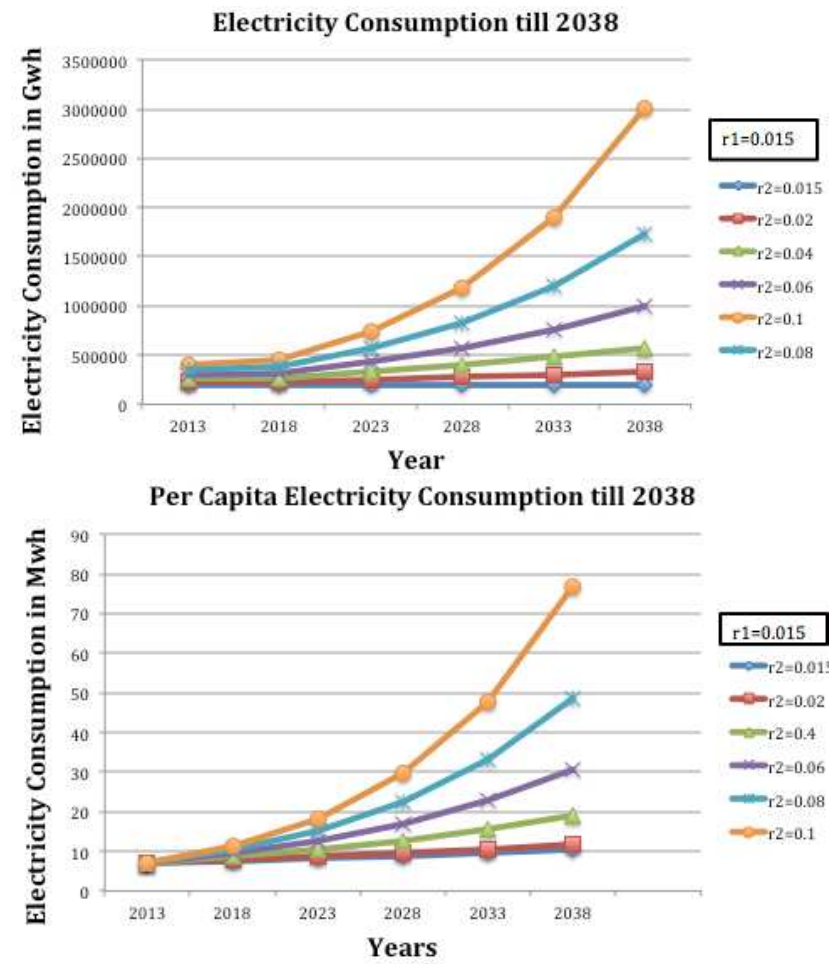

Figure 4: Projected total electricity consumption (top) and per capita electricity consumption (bottom) as calculated using Equation (1) and assuming $r_{1}=0.015$ and $r_{2}=0.015,0.02,0.04,0.06,0.08$ and 0.1

\section{Renewable Energy As Source of Electricity in Saudi Arabia}

Due to its vast oil reserve and generous oil supply within the country, Saudi Arabia has not so far developed and utilized its abundant renewable energy resources. Its geographic location gives it a big advantage in the area of solar energy. The average solar radiation in the Middle East is about $6-7 \mathrm{kWh} / \mathrm{m}^{2} /$ day. In comparison, the average solar radiations in Germany and USA, which have the most developed solar industry, are 4 and 4-5.5 $\mathrm{kWh} / \mathrm{m}^{2} /$ day, respectively. Unlike many countries in the world, solar radiation in Saudi Arabia is high throughout the year, and as shown in Figure 5, it ranges between 3 to $4 \mathrm{kWh} / \mathrm{m}^{2} /$ day in the winter months and 6 to 7.7 $\mathrm{kWh} / \mathrm{m}^{2} /$ day in the summer months. Saudi Arabia also has great potential for utilizing wind energy, since wind speeds in its coastal areas along the Arabian Gulf in the east and Red Sea in the west are 14-22 km/h and 16-19 $\mathrm{km} / \mathrm{h}$, respectively. However, since solar radiation in Saudi Arabia is more consistent and predictable than wind speed, solar energy is being considered the primary renewable energy source in the country.

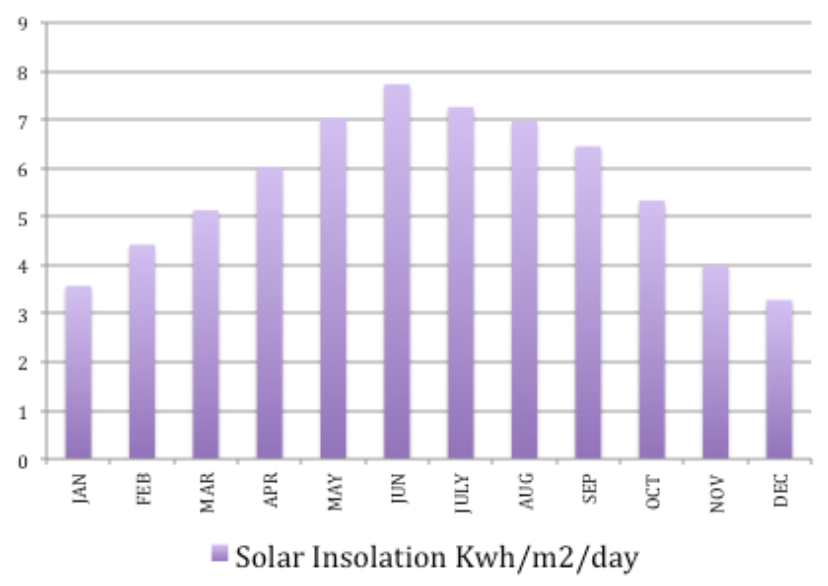

Figure 5: Monthly solar insolation in Saudi Arabia

Saudi Arabian government's recently announced investment for $54 \mathrm{GW}$ of renewable power will include 41 $\mathrm{GW}$ of solar power, $9 \mathrm{GW}$ of wind power, $3 \mathrm{GW}$ from waste to energy, and the remaining $1 \mathrm{GW}$ from geothermal sources. Out of $41 \mathrm{GW}$ of solar power electricity, $16 \mathrm{GW}$ will come from photovoltaic (PV) panels and $25 \mathrm{GW}$ will come from concentrated solar power (CSP) plants. Saudi Arabia also plans to develop 16 nuclear reactors producing $14 \mathrm{GW}$ of nuclear power by 2030. This breakdown clearly indicates that Saudi Arabia is considering a mix of renewable energy sources to augment its declining oil supply and to meet increasing demand for electricity $[8,9]$. However, as can be seen in the breakdown of renewable energy investment, solar energy will be its primary renewable energy source for electricity.

Addition of renewable energy to the energy source mix will not only increase the electricity supply, but also reduce the dependence of oil for electricity generation. It is estimated that if solar energy is adopted in the Middle Eastern countries, the entire region can save 
between $\$ 300$ million to $\$ 1$ billion yearly [10]. Concurrently, fossil fuels that are used for electricity generation will also extend for longer years. Another key benefit will be the reduction of greenhouse gas (GHG) emission. In 2009-2010, Saudi Arabia generated 542.1 million metric tons of $\mathrm{CO}_{2}$ equivalent, which is the 18th largest, and on per capita basis, the 21 st largest in the world.[11]. The major source of GHG emission was the energy sector, which produced $71.6 \%$ of the GHG produced in Saudi Arabia. Solar energy has very little GHG emission, and as it replaces part of the GHG producing fossil fuels for electricity production, it will help in mitigating the GHG gas emission. Similarly, according to the Clear Sky Advisors' analysis, with recent improvement of solar energy technologies, the price of large-scale solar photovoltaic cells has become less than $\$ 0.15 / \mathrm{kWh}$, whereas burning oil costs around $\$ 0.127$ $0.174 / \mathrm{kWh}$ in Saudi Arabia [12]. Thus the electricity generation cost using solar energy is becoming competitive to that generated by fossil fuels. By combining solar energy and fossil fuel will give Saudi Arabia the potential to meet its power demand. The excess of solar and other renewable energies can be exported to other countries and will open a new financial resource for the country as well [13].

\section{Smart Grid in Saudi Arabia}

The electricity distribution to its residential, commercial, industrial and other domestic customers in Saudi Arabia is based on the traditional grid system. Like many countries in the world, Saudi Arabia is beginning to consider smart grid as an alternative to traditional grid. Saudi ARAMCO, for example, has initiated several small projects in which elements of smart grid system has been introduced [14].

The advantages of smart grid over traditional grid are many [15] [16]. For example, traditional grid is characterized by one-way flow of electricity from the electricity suppliers to the customers and it does not allow automatic and remote interactions between suppliers and customers or between the production and distribution facilities. Thus, when there are overloads, line failures, faults or blackouts, the traditional grid system cannot respond immediately, and depending on the problem encountered, it may take several minutes to several days to restore the normal flow of electricity. Smart grid, on the other hand, through its network of sensors, computer controls and advanced software, can immediately detect the line problem and take the necessary corrective actions. Furthermore, it has the self-healing capability so that it can easily isolate the affected areas and redirect power flow around the damaged facilities. Smart grid also involves the customers in managing the electricity flow to overcome the peak load on the power grid

One of the advantages of smart grid is that it can respond to peak electricity demand much more quickly than traditional grid. This will be one of the key advantages of adopting smart grid system in Saudi Arabia, since it will help meet the electric power supply need in peak demand times. The reliability of electricity supply in Saudi Arabia, which suffers from frequent blackouts in hot summer months, will also improve when smart grid system is integrated with renewable energy sources. While renewable energy sources will be able to deliver additional electricity needed to meet power demand during summer months, smart grid will be able to diagnose the disruption in power supply, take corrective actions automatically with very little manual input, and thus improve reliability of power delivery. It can also direct or redirect power to areas where it is needed during blackouts or peak demand hours.

As shown in Figure 6, peak power demands in Saudi Arabia have ranged from 40 to $50 \mathrm{GW}$ in the months May through October in 2012. Increasing use of air conditioners is the primary reason for peak demand during these months when the average temperature varies between 38 and $43^{\circ} \mathrm{C}$ and the daily mean temperature varies between 32 and $36^{\circ} \mathrm{C}$. Figure 7 shows the daily peak demand in typical summer and winter months. During summer days, it fluctuates between 38 and $42 \mathrm{GW}$ much of the day except from 4 AM to 10 AM. During these peak demand periods, renewable energy source can supply the additional power to reduce the overload on the fossil fuel plants or reduce the consumption of fossil fuel for electricity production.

Figure 6 also shows the projected peak demand variation in 2038. The calculation for the projected peak demand is made using Equation (1) and assuming $r_{1}=0.015, r_{2}=$ 0.02 and the peak demand values in 2012 as the initial values. The highest peak demand in June-July is shown to be $116 \mathrm{GW}$, which means that even with $54 \mathrm{GW}$ of electricity produced from renewable energy, the peak demand cannot be met in 2038 without additional capacity of power generation.

\section{Maximum Montly Demand Variation in Saudi Arabia}

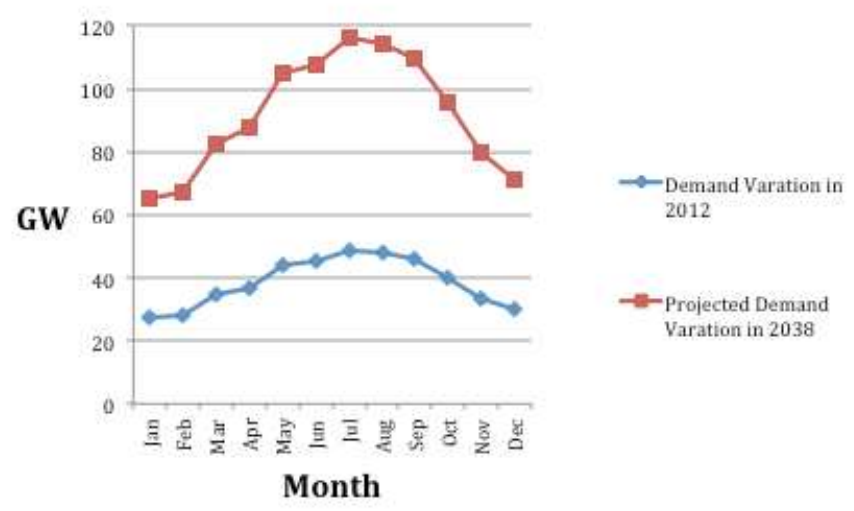

Figure 6: Maximum monthly demand variation in 2012 (actual) and 2038 (projected value using Equation (1), $r_{l}=0.015$ and $r_{2}=0.02$ )

Figure 8 shows an example of how the electricity demand can be met by dividing the power generation between the solar energy and fossil fuel. The total power demand in the year 2012 is used in this example, which is calculated as 2273.3 billion $\mathrm{kWh}$ by summing up the month-by-month average power demands in the eastern, central, western and southern sectors. It is assumed in Figure 8 that in summer months when solar insolation is at its peak (as shown in Figure 5), power supply from solar 
energy will be higher than the power supply from fossil fuel. In winter months, solar insolation is lower, and therefore, power supply from solar energy will be lower. It is assumed that during the months of May through September, $70 \%$ of the power supply will come from solar energy and $30 \%$ will come from fossil fuel. On the other hand, in January, February and March, $70 \%$ of the power supply will come from fossil fuel and $30 \%$ will come from solar energy. During the other four months of the year, the power supply will be divided as $60 \%$ from fossil fuel and $40 \%$ from solar energy. Month-by-month power supply between fossil fuel and solar energy is shown in Figure 8 . The total power demand of 273.3 billion $\mathrm{kWh}$ in 2012 came from fossil fuel only.

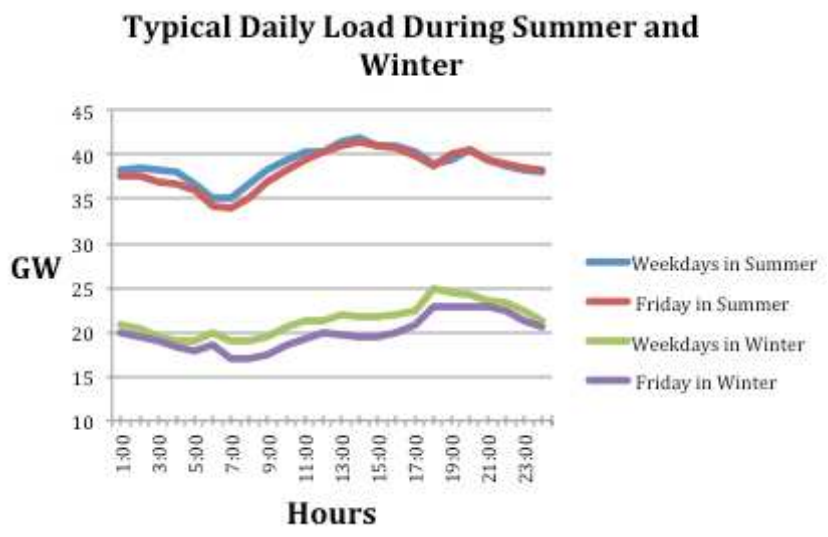

Figure 7: Typical daily peak load in summer and winter month in 2012

If the power supply is divided between fossil fuel and solar energy, then it is estimated that 126.2 billion $\mathrm{kWh}$ will come from fossil fuel and the remaining 143.3 billion $\mathrm{kWh}$ will come from solar energy. Assuming that $1 \mathrm{kWh}$ of electricity generation requires 0.00188 barrels of oil, the number of barrels of oil needed for power supply will reduce from 514 million barrels if only fossil fuel is used to 237 million barrels if solar energy is used alongside fossil fuel. This represents a 53\% decrease in fossil fuel use for power supply in the example year of 2012.

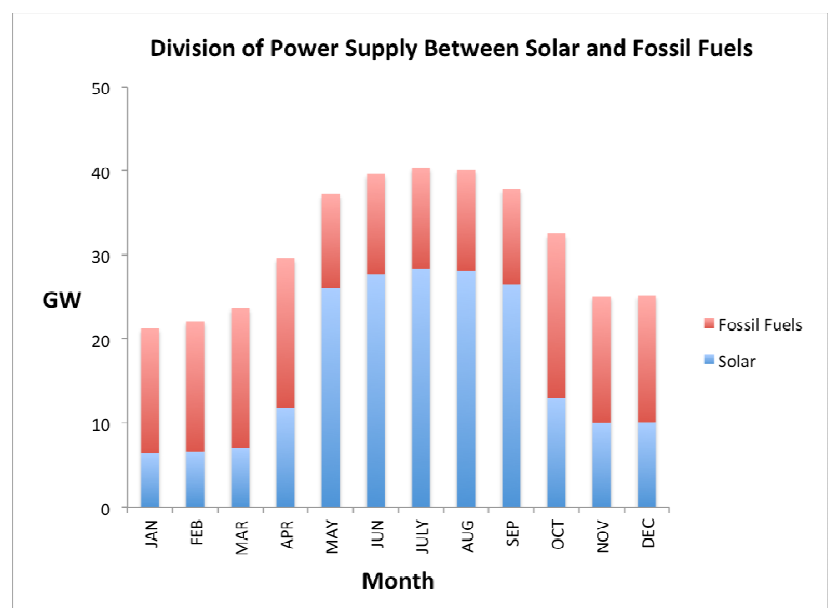

Figure 8: Division of power supply between solar and fossil fuels to meet power supply (Year 2012 is used in this example plot)

\section{Smart Grid Implementation and Intergration of Solar Energy}

Saudi Arabia, like many other countries in the world, is starting to realize the significance of renewable energy and overcome the challenges in integrating renewable energy in the electric grid system. To be more effective, smart grid should also be implemented and integrated with renewable energy sources to assure reliability and flexibility in power supply. In addition to the government sponsored and built centralized solar power plants, incentives should be provided for individual families, office buildings and industrial companies to install their own solar panels. Such distributed generation can be relatively easily integrated if smart grid is adopted. Bi- or multi-directional electricity flow between the distributed generation locations and power supply utilities will provide additional power to the grid during peak times. During non-peak times, unused power can be stored for either emergency or peak-time use. However, this will require building power storage facilities around the country. Unused power can also be transmitted and sold to neighboring countries, which will then become a source of revenue for the country.

There are already plans to link the countries in the Middle East and North Africa (MENA) to seamlessly and intelligently transmit and share electric power among each other. This will reduce the number of electricitygenerating plants, increase reliability and efficiency of power supply and decrease GHG emission from the region [13]. By engaging customers in the highly automated smart grid system, it is estimated that a reduction of up to $10 \%$ of the usual power loss in transmission can be avoided [17]. It is also estimated that smart grid will be able to decrease GHG emission between 5-9 \% of the 2005 levels [18]. A recent report shows that if smart grid is implemented connecting the MENA countries, there will be an annual saving of $\$ 300$ million to $\$ 1$ billion for the countries involved [19].

While transitioning from traditional grid to smart grid will require costly initial investment, studies have shown that the benefit-to-cost ratio of smart grid can be in the range of 2.8 and 6 [19]. Investments will be required in modernizing transmission lines and substations, installing energy storage devices, digitizing distribution and electricity flow control, monitoring consumer engagement, creating technically skilled workforce and educating citizens of the country about the need for and benefits of renewable energy and smart grid. Among the key technologies that need to be considered for smart grid are:

(1) Integrated two-way communication and highspeed digital data delivery

(2) Automatic sensing, dynamic monitoring and realtime measurements

(3) Smart metering, which will automatically monitor electricity consumption by each user and adjust

(4) Energy storage, which is most likely be an advanced battery system 
(5) Intelligent control, switching and coordination between generation, storage and distribution

There are many challenges in implementing the technologies needed for smart grid. Two of these challenges are more of education and training issues than purely technical and technology issues. One of these challenges is to educate consumers on the use and benefits of smart grid so that they can utilize the options available to manage their own electricity consumption and effectively reduce their electricity bills. Lack of customer awareness and knowledge about smart grid is one of the reasons mentioned for slow implementation of smart grid in the European Union [20]. Installation of smart meters in each household is the first step in that direction, but the value of smart meters may not be clearly understood by the customers. It is interesting to note that Saudi Arabia and United Arab Emirates have already set a goal by installing $86 \%$ of their homes with smart meters in 2020 [19]. Another challenge is to create a technically skilled and science-educated workforce who will understand the complex nature of smart grid implementation. Currently, more than 900,000 Saudi Arabian students are pursuing science and engineering degrees in various universities within the country, which is approximately $50 \%$ of the 18 to 24 age groups. Saudi Arabian government is providing scholarships and other incentives for Saudi Arabian students to travel to USA and other countries for higher education in engineering and computer science. There are currently about 70,000 Saudi Arabian students in American universities. According to the most recent report by the Institute of International Education, Saudi Arabia is the fourth largest provider of international students to US universities after China, India and South Korea. Thus, it appears that within the next 5 to 10 years, Saudi Arabia will have an adequate capacity of skilled human talent needed for renewable energy and smart grid technologies.

\section{Conclusion}

Saudi Arabia has been a dominant country in the world oil market for a long time by being the largest oil producer as well as the largest oil exporter in the world. However, its oil export may not remain at high level due to increasing use of oil in domestic electricity generation. Saudi Arabia has announced an ambitious plan to invest in renewable energy, particularly in solar energy. Research and development in solar industry is the first step taken toward achieving the plan. It is suggested in this study that in order to make the renewable energy effective in electricity generation, it should be integrated with smart grid. The challenges in the integration process are briefly outlined.

Saudi Arabia's energy policy is in transition. This gives an opportunity to formulate the framework of development, standards and regulations regarding the technologies to be adopted or developed, feed-in-tariff, power transaction, taxes and incentives, etc. of the renewable energy market. The installation of renewable energy and smart grid systems may require large-scale private investment. The overall energy policy should flexible so that it is easily negotiated between the government and the investors.

\section{References}

[1] "Saudi Arabia", Central Intelligence Agency. [Online], Available: https://www.cia.gov/library/publications/theworld-factbook/geos/sa.html

[2] Akhonbay, H, "Saudi Arabia's Energy Policy", Center for Strategic and International Studies, August, 2012.

[3] Clay, R, "Saudi Arabia to Unleash Solar by Investing \$109 Billion", The Energy Collective, May, 2012.

[4] Steyn, C and Norman, M, "Saudi Arabia: The Future Solar Leader", Chadbourne\& Parke LLP, Nov. 2012.

[5] Brown,J, "A Quantitative Assessment of Future Net Oil Exports By the Top Five Net Oil Exports", GraphOilogy/Energy Bulletin, Jan.2008.

[6] "Saudi Arabia", U.S Energy Information Administration, Feb.2013. [Online], Available: https://www.eia.gov

[7] Lahn, G. and Stevens, P., "Burning Oil to Keep Cool - The Hidden Energy Crisis in Saudi Arabia", Chatham House, Dec.2011. [Online], Available: https://www.chathamhouse.org

[8] Bachellerie, I. J., "Renewable Energy in the GCC Countries : Resources, Potential and Prospects", Gulf Research Center, March 2012.

[9] Alnatheer, O., "The potential contribution of renewable energy to electric supply in Saudi Arabia”, Energy Policy, Vol. 33, 2005, pp. 2298-2312.

[10] "GCC Can Save \$ 1bn with Smart Grid", Emirates, June.2012. [Online], Available: http://www.emirates247.com/

[11] Doha Carbon and Energy Forum 2013, Briefing Paper on Climate Change, Brookings Institution, October 2013. Available: http://www.dcef-qatar.org/app/media/7945

[12] Deaves, M. "Solar achieves grid parity in Saudi Arabia Significant developments expected", ClearSky Advisors, Feb. 2013 [online]

Available: http://www.clearskyadvisors.com/3207/solarachieves-grid-parity-insaudi-arabia-significantdevelopments-expected/

[13] "Desertec will supply the European Market with clean energy from African solar plant", Softpedia, Nov. 2011. Available: http://news.softpedia.com

[14] Ghanam, S.H.,Shahrani, B.S., Essa, A.S., Hamrani, M.M., Dubaikel, F.A., Awami, A.T., "Saudi ARAMCO's efforts in smart grid", IEEE PES Conference on Digital Object Identifier, 2011.

[15] Farhangi, H, "The Path of the Smart Grid", IEEE Power \& Energy Mag., Issue 1, pp.18-28, February, 2010.

[16] "Smart Grid Analysis", National Energy Technology Laboratory, [Online], Available: http://www.netl.doe.gov/

[17] Gevorkian, P., "Large-Scale Solar Power System Design: An Engineering Guide for Grid-Connected Solar Power Generation", McGraw-Hill, 2012.

[18] Abdullah, L and El-Shennawy, T, "Reducing Carbon Dioxide Emissions from Electricity Sector Using Smart Electric Grid Applications", Hindawi Publishing Corporation, January.2013.

[19] "Estimating the Costs and Benefits of the Smart Grid", Technical Report, Electric Power Research Institute, Palo Alto, CA, March 2011.

[20] Giglioli, E., Panzacchi, C., and Senni, L., "How Europe is Approaching Smart Grid", Mckinsey \& Company, 2010. 